\title{
The influence of the quality in daycare environments on children's motor development between six to 15 months old
}

Keli Lovison 1

iD https://orcid.org/0000-0002-1494-0146

Helenara Salvati Bertolossi Moreira 2

iD https://orcid.org/0000-0001-6718-2409

Joselici da Silva 3

iD https://orcid.org/0000-0003-3085-7681

Luiz Guilherme Dacar Silva Scorzafave 4

iD https://orcid.org/0000-0003-2044-4613

Débora Falleiros de Mello 5

(iD https://orcid.org/0000-0001-5359-9780

1,3,5 Programa de Pós-Graduação Enfermagem em Saúde Pública. Escola de Enfermagem de Ribeirão Preto. Universidade de São Paulo. São Paulo, SP, Brasil. E-mail: keli.lovison@hotmail.com

2 Universidade Estadual do Oeste do Paraná. Cascavel, PR, Brasil.

4 Faculdade de Economia, Administração e Contabilidade de Ribeirão Preto. Universidade de São Paulo. São Paulo, SP, Brasil.

\begin{abstract}
Objectives: to analyze the influence of the quality in the environment on children's motor development between six to 15 months old attending early childhood education centers.

Methods: a cross-sectional and analytical study addressing children's motor development between six to 15 months old, both sexes, enrolled in nursery (0-12 months) and preschoolers (12-24 months). The Affordances in the Home Environment for Motor Development-Infant Scale and Alberta Infant Motor Scale were used in the Brazilian versions

Results: the sample was comprised of 104 children and 30 early childhood education centers: presenting a mean age of 9.15 months, $88 \%$ attended full-time and $12 \%$ part-time schooling (mornings or afternoons). One center was classified with a low Affordances, 26 were considered Sufficient, and three were Adequate. Of the participating children, $40 \%$ presented typical motor development. The higher levels of Affordances suggest better motor development, and lower levels of suspected delayed motor development.

Conclusion: the environments of early childhood education centers influence children's motor performance, especially daily activities and the use of toys. The lower the Affordances level, more likely children are suspected of delayed motor development.

Key words Day care centers, Babies' development, Child
\end{abstract}

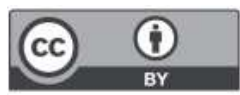




\section{Introduction}

The first years of life constitute a meaningful human developmental phase for the formation of the structures and functions of the brain, which it presents greater plasticity to environmental stimuli, enabling children to improve abilities and potentialities for life.1-3 Cognitive, attention, memory, problemsolving capacity, and critical thinking skills, together with socioemotional aspects, are related to a range of experiences in the first years of life.4-6

Motor skills are among the most remarkable milestones in children's first year of life.3,7 and delayed motor skills need to be detected to predict skills in other stages of life, especially those related to cognition and language. 8,9

Environments that promote enriching and stimulating experiences in the first years of life are crucial for a child's development. 10 High-quality early childhood education is related in promoting the children's development by expanding learning experiences, along with good health conditions, nutrition, safety, protection, and responsive care.11 A study conducted in the Brazilian daycare settings and preschools reports that activities, personal care routines, and the structure of educational programs were the aspects in which quality was the most compromised, showing that changing specific characteristics of these institutions might improve the quality of child's education. 12 Therefore, the quality in the environments can promote child development, and children attending high-quality daycare are more likely to achieve good developments. ${ }^{13}$

Controversies reported in the literature concerning how the quality of a daycare environment influences children's motor development $2,7,8$ motivated this study, considering it is highly relevant to detect early and timely any delayed motor skill development. Hence, this study has the objective to analyze the influence of the quality of environments on children's motor development between six to 15 months old attending early childhood education centers.

\section{Methods}

This cross-sectional and analytical study evaluated the children's motor development between six to 15 months old, both sexes, regularly enrolled in Centros de Educação Infantil (CEI) [early childhood educational centers], attending nursery (0-12 months) or preschoolers (12-24 months), in Cascavel, PR, Brazil.

Inclusion criteria were children between six to
15 months old, both sexes, living in Cascavel, PR, Brazil, not enrolled in any specific monitoring programs or to any child development interventions. Children with cognitive, motor, sensorial or behavioral dysfunctions, congenital malformations, genetic syndromes, neurological impairment, or visual or hearing impairments were excluded. Children who did not complete the evaluation due to either crying or indisposition were considered missing data.

This study was a convenience sample according to the number of children enrolled in daycare centers. In each Centro Municipal de Educação Infantil (CMEI) [Municipal Child Education Center], the first four children whose parents or legal guardians authorized their participation in the study were evaluated for motor development. Thirty of the 37 CMEIs existing at the study setting, met the inclusion criteria and were for nursery, preschoolers, or mixed classes. Data were collected from April to December 2018.

The Brazilian validated version of the Affordances in the Home Environment for Motor Development - Infant Scale (AHEMD-IS) was used to evaluate the quality of the daycare environments. 14 This scale was initially developed to evaluate the influence of the children's motor development in a home environment but it was recently adapted to also evaluate daycare settings. 15 The evaluation focuses on Affordances, that is, opportunities for children to develop motor skills considering daycare characteristics such as outdoor space (three questions dichotomous type), and indoor space (three questions dichotomous type), a variety of daily stimulation (five questions type Likert), toys, andexisting materials at daycare (15 questions -9 questions type Likert on fine motor skill toys: six questions type Likert on gross motor skill ).

The scoring on the physical space is the dichotomous type (no $=0$ points and yes $=1$ point) daily activities type Likert is (never $=0$, sometimes $=1$, almost always $=2$, and always $=3$ ), and for toys is (none $=0$, one or $t w o=1$, three or four $=2$, five or more $=3$ ). The total score of the items is classified in opportunities: Weak Affordances (0-20 for children below 12 months and 0-22 for children above 12 months), Sufficient Affordances (21-40 for children younger than 12 months and 23-44 for children older than 12 months), or Adequate Affordances (41-60 for children younger than 12 months and 45-66 for children older than 12 months). Items 1 to 19 are applied for children younger than 12 months, and items 20 to 26 are applied for the older ones. 14 
During the data collection two researchers stayed in each CMEI to observe the environments (indoors and outdoors physical structure), the staff (principals, teachers, and caregivers), the children, and time, spaces, and activities were organized. Data collection lasted approximately three hours in each CMEI.

The Escala Motora Infantil de Alberta (Alberta Infant Motor Scale (AIMS) was validated and used to evaluate the children's motor development among the Brazilian population. 16 AIMS was developed in Canada to measure motor maturation among children from birth through independent locomotion phase at around 18 months of age. It is composed of 58 items that describe the development of spontaneous movements and motor skills in four basic positions: prone (21 items), supine (nine items), sitting (12 items), and standing (16 items). The items are presented in the form of drawings, arranged in a prospective order of development in each position, and are accompanied by specific criteria that consider the children's weight bearing, posture, and antigravity movements. 17

Three trained physical therapists were applied by AIMS in this investigation study for the use of the scale, and the inter- and intra- reliability of the examiners were verified. The time applied by AIMS was 20 to 30 minutes, and some of this time was used for the children to get themselves comfortable with the test.

Scoring begins by determining the less to the most developed item in each of the four postures, establishing each child's "motor skills range". Within this range, the items are classified as: Observed (O - score 1) and Not Observed (NO score 0$)$. All the items found before this range are scored one point each. Next, these scores are added to the scores of the items within the range to obtain the score of each subscale, and the sum of the four subscales scores result in the total gross score. The total gross score and the child's age are plotted on a chart available on the test sheet, and the percentile corresponding to the child's gross motor skill is identified. The itemsobserved in each posture are summed, resulting in the total score ( 0 to 58 points). Afterwards, the scores are transferred to the AIMS chart according to the child's age (months). The percentile corresponding to the child's motor development is classified according to the following criteria: below $25 \%$ (suspected of delayed development, especially the percentile values of $5 \%$ and $10 \%$ ), above $25 \%$ (adequate motor development) whereas $50 \%$ and $75 \%$ are considered normal to excellent, and above $90 \%$ is considered excellent when performing all the movements described in the scale.. 17

Data concerning the CMEIs' characteristics were analyzed using descriptive statistics to improve the recognition of the environments in this study. The Chi-square test of independence was applied, followed by residual follow-up, adjusted to analyze the frequencies of motor development classifications and linear correlation to evaluate the Affordances of the CMEIs. The analyses were performed using XLSTat version 2016, considering the significance level of $5 \%$

This study was approved by the Institutional Review Board at the Escola de Enfermagem de Ribeirão Preto da Universidade de São Paulo, opinion report number: 66265617.2.0000.5393.

\section{Results}

The sample was composed of 104 children, the mean age was 9.15 months old; $57 \%$ were females. Of the children enrolled in the CMEIs, $88 \%$ attended fulltime and $22 \%$ part-time (mornings or afternoons). One out of 30 CMEIs was classified as Weak Affordances, 26 Sufficient Affordances, and three Adequate Affordances.

Table 1 presents the characteristics of the CMEIs in relation to the number of rooms (except restrooms teacher's room, and kitchen), the number of teachers and staff involved with children's daily care in each classroom, the teachers' and staffs' schooling level, and the total number of children per classroom were analyzed.

The comparison of Affordances of the CMEIs according to the scores obtained for the physical space, daily activities and toys, observed that the higher the score, the better the dimensions. A statistically significant difference was found between daily activities $(\mathrm{R}=0.87, p=6.7-10)$ and toys $(\mathrm{R}=0.7$, $p=1.7-0.5)$. As shown in Figure 1, no statistically significant difference was found for the dimension of the physical space $(\mathrm{R}=0.3, p=0.1)$.

Daily activities and toys for fine and gross motor development were the most influential factors in the quality of the daycare environments. The physical space (outdoor and indoor space) was the least influential.

Regarding to children's motor development, Figure 2 shows that $40 \%$ of the children was possible to present typical motor development. When evaluating children's motor development according to the classification of each CMEI in terms of Affordances, a statistically significant difference was found between suspected and excellent motor development 
categories $\left(\chi^{2}=9.058 ; p=0.026\right)$.

The comparison between classifications revealed that most children attending daycare centers presented excellent motor skills and were classified as Adequate Affordances. In contrast, most children suspected of delayed motor development attended daycare centers classified as Weak - Sufficient Affordances $(p=0.01)$. The remaining categories did not present statistically significant differences $(p=0.13)$ (Figure 3).

\section{Discussion}

Most of the 30 CMEIs participants presented Sufficient Affordances with good physical conditions and stimulation, suggesting that there are opportunities for children to develop their motor skills.

The factors that most influenced the quality in the daycare environments included daily activities and toys that promoted fine and gross motor skills, whereas the indoor and outdoor physical spaces had little influence.

The daycare environments are an essential factor to promote development in the first years of a child's life, and many countries are expanding CEIs access for children. ${ }^{11,18}$ In addition, good physical conditions and stimulations are vital for children to develop appropriately, including opportunities to play, have proper nutrition and hygiene, and contact with other children. ${ }^{19}$ Another aspect concerning the quality in child education refers to respecting children's fundamental rights, ${ }^{20}$ which are extremely relevant to ensure children's development to their full potential.

The quality of preschool centers has various dimensions that concern the physical environment, classroom size, teachers /children ratio, and teachers' training, which refer to safety promotion. ${ }^{21,22}$ The number of rooms in the institutions analyzed in this study and the teachers-children ratio were adequate.

The physical environment had very little influence in the quality in the daycare center environments, considering that the used scale only addressed three aspects of the indoor space and three aspects of the outdoor space. The indoor space should have included a nursery, a playroom with appropriate and safe toys, living and eating areas, while the outdoor space should have a covered playroom area including toys with wheels, hanging toys, swings, balls, and an open space area with equipment that allowed children to climb, slide, and encourage children to explore the outdoor area and toys. 23

One of the factors that influence the quality of education the most is the professionals' educational level that work with these children. In this study, the teachers had a Higher Education degree while most of the staff had incomplete Higher Education. Therefore, adequately trained teachers receiving decent salaries and supported by the leaders of the school, pedagogical coordinators, and the remaining professionals, working as a team according to a reflexive process, and constantly improving their practices, are vital to build a high-quality preschools. 24

The Brazilian context requires workers to look more attentively to the different situations in preschools to verify the difficulties concerning physical, material, and human resources, aspects that directly interfere with a daycare routine, 25 corrobo-

\section{Table 1}

Characterization of CMEls according to the number of rooms, staff, professionals' schooling level, and the number of children. Cascavel, PR, Brazil, 2018.

\begin{tabular}{lccc}
\hline Characteristics of CMEls & Weak - & Sufficient - 26 & Adequate - \\
\hline Number of rooms $(\mathrm{m})$ & 5 & 3,6 & 5,6 \\
Number of teachers $(\mathrm{m})$ & 1 & 1,6 & 1 \\
Number of staff $(\mathrm{m})$ & 1 & 1,7 & 2 \\
Teachers' schooling & $1 \mathrm{CHE}$ & $20 \mathrm{PG}$ & $1 \mathrm{PG}$ \\
& & $23 \mathrm{CHE}$ & $2 \mathrm{CHE}$ \\
Staff's schooling & $1 \mathrm{CHE}$ & $30 \mathrm{IHE}$ & $2 \mathrm{IHE}$ \\
& & $16 \mathrm{CHE}$ & $1 \mathrm{CHE}$ \\
Total number of children in the classroom $(\mathrm{m})$ & 15 & 17,6 & 14,6 \\
\end{tabular}

$\mathrm{CMEI}=$ Municipal Child Education Center; $\mathrm{m}=$ mean; $\mathrm{PG}=$ Post Graduation degree; $\mathrm{CHE}=$ Complete Higher Education; $\mathrm{IHE}=$ Incomplete Higher Education. 


\section{Figure 1}

Affordances on CMEIs considering dimensions (physical space, daily activities, and toys). Cascavel, PR, Brazil, 2018.
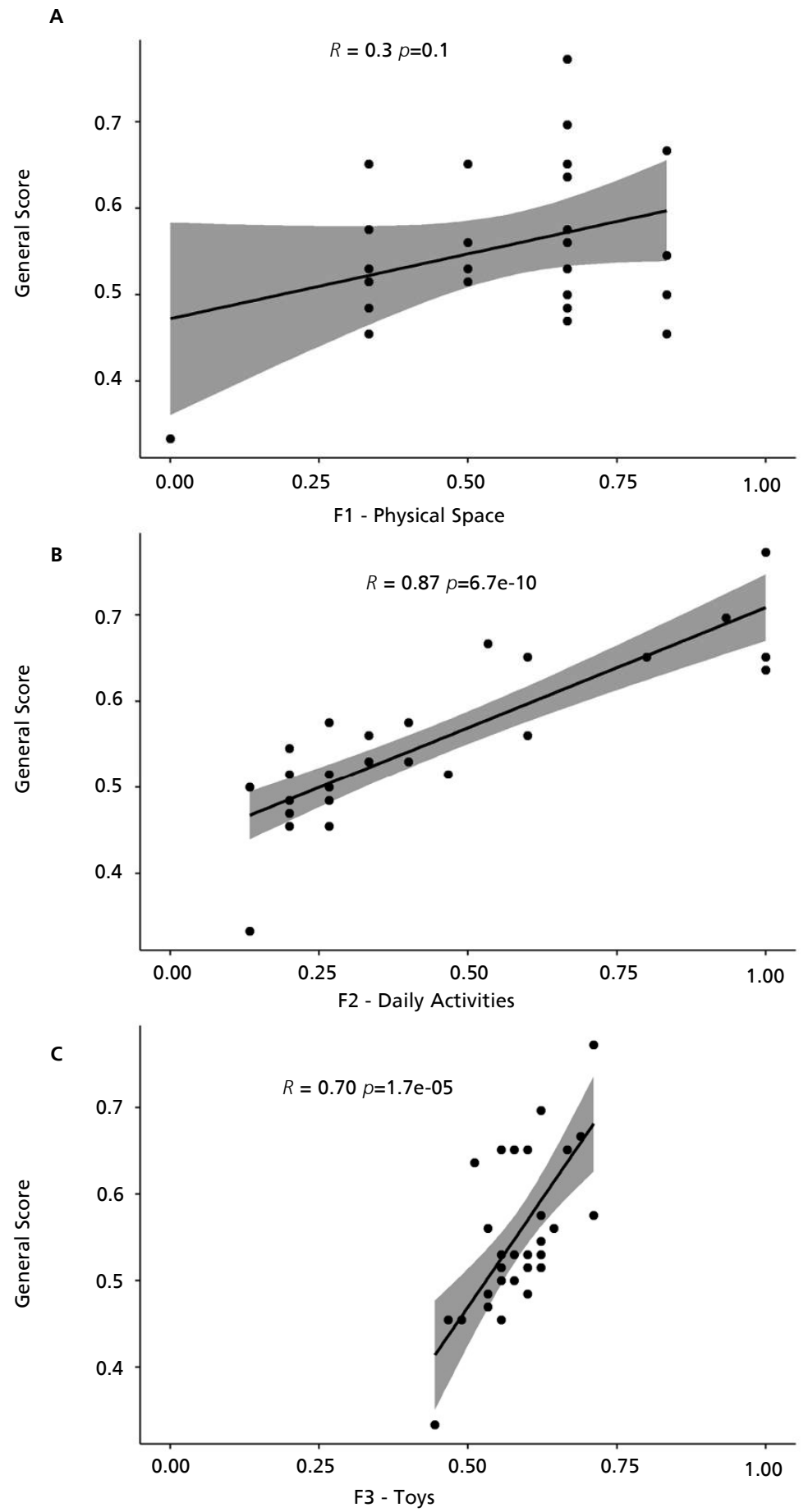

Statistically significant difference $(p<0.05) . \mathrm{CMEI}=$ Municipal Child Education Center 
Classification of children's motor development enrolled in the CMEls. Cascavel, PR, Brazil, 2018.

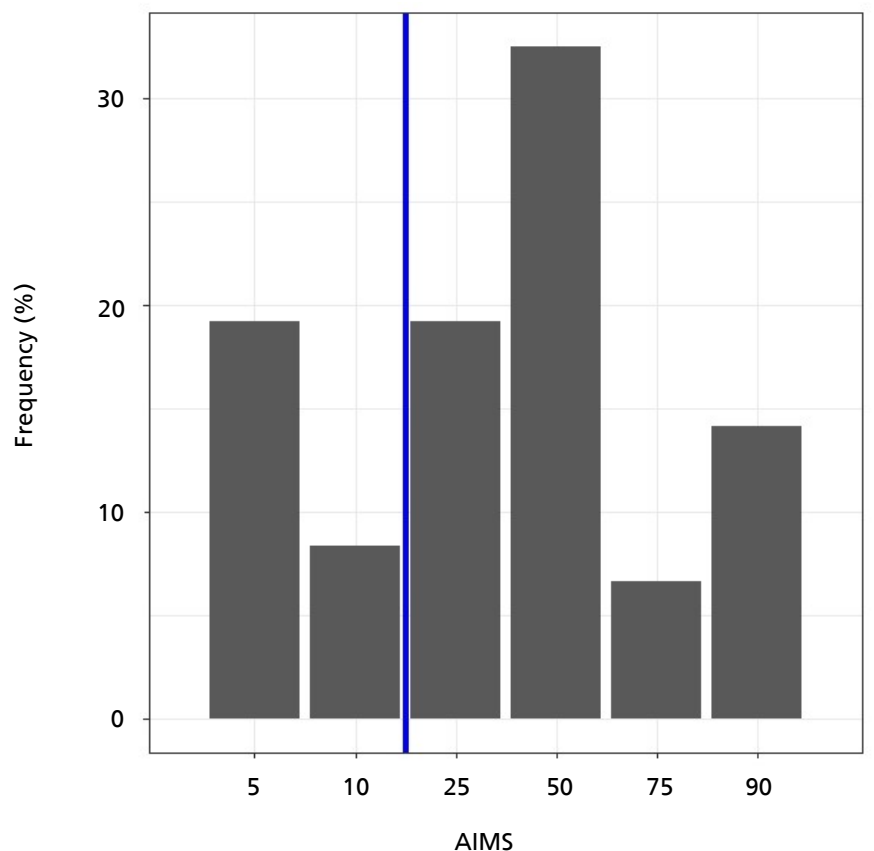

Cut-off point: below $25^{\text {th }}$ percentile (suspected of delayed motor development, especially the $5^{\text {th }}$ and $10^{\text {th }}$ percentile values) and above $25^{\text {th }}$ percentile (adequate, normal or excellent motor development). CMEI = Municipal Child Education Center.

Figure 3

Children's motor development according to the Affordances of CMEIs. Cascavel, PR, Brazil, 2018.

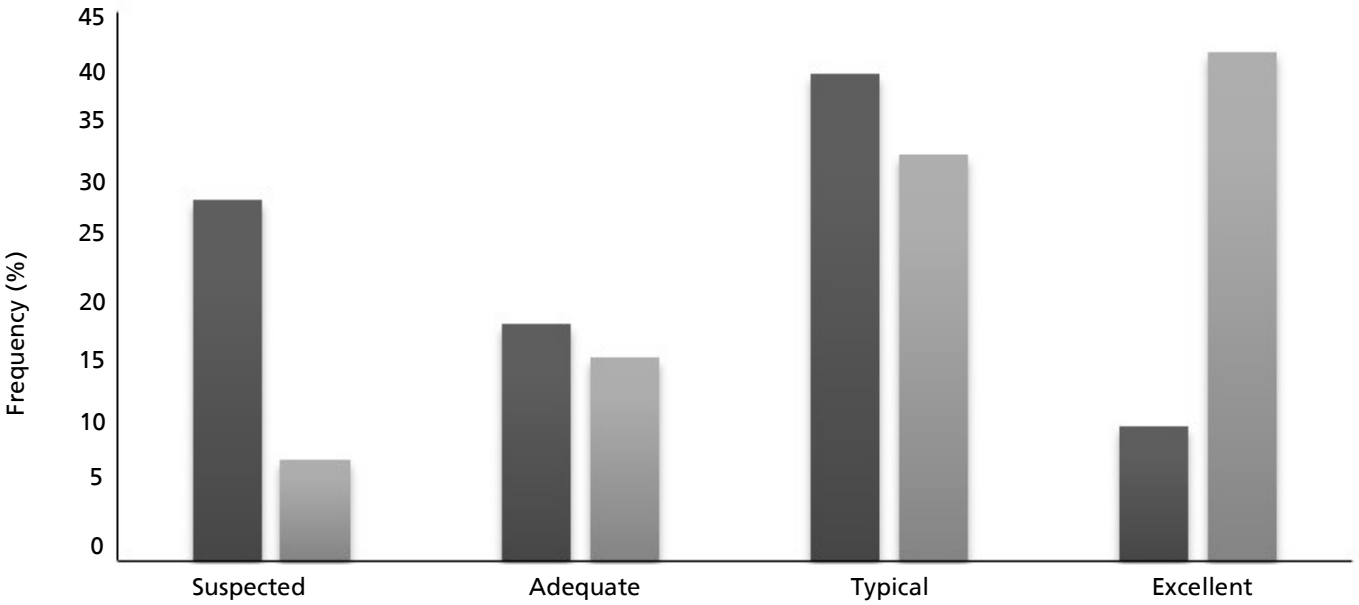

AIMS 
rating with these results in this study which the factors that most influenced the quality in the daycare centers were daily activities and toys that promote fine and gross motor development.

A relevant issue in the political agenda of many developed countries is how much attention is paid in children's formal care and consequently, the effect of expanding the hours in preschools. ${ }^{26}$ In the analyzed CMEIs, $88 \%$ of the children are full-time (eight hours a day) and 22\% part-time (mornings or afternoons, four hours a day) schooling. Longer weekly hours at daycare are considered as a factor that decreases the prevalence of risks in motor development, especially among children facing social vulnerability; however, they may also negatively affect the children's socioemotional wellbeing and render them to more susceptible respiratory problems. 27

Comparing the children's motor development and the classification of schools $\mathrm{s}$ in terms of Affordances, revealed that children attending highquality CMEIs presented excellent motor development and a lower risk of delayed motor development.

Therefore, children attending public or private daycare centers must receive high-quality stimuli to promote child development. For example, a study identified that stimulating environments in which children meet regularly and are cared for by certified pedagogical personnel favored motor skill developments and helped immigrant children to accelerate their progress to acquire linguistic competencies. 18

This study focused on the setting of the CMEIs and the limitations include the need to analyze the families' sociodemographic characteristics, including the maternal antecedents, whether the mothers have a paying job, the quality of home environment for children who are not enrolled in a daycare, and the quality of care and stimuli provided

\section{References}

1. Shonkoff JP. Protecting brains, not simply stimulating minds. Science. 2011; 333: 982-3.

2. Shonkoff JP, Fisher PA. Rethinking evidence-based practice and two-generation programs to create the future of early childhood policy. Dev. Psychopathol. 2013; 25: 163553.

3. Haywood KM, Getchell N. Desenvolvimento motor ao longo da vida. 6 ed. Porto Alegre: Artmed; 2016.

4. Fox S, Levitt P, Nelson CA. How the timing and quality of early experiences influence the development of brain architecture. Child Development. 2010; 81: 28-40.

5. Bick J, Nelson CA. Early adverse experiences and the for children throughout their routines, which are also inter-related to child's motor development.

Merely analyzing the results obtained in the scales to evaluate the quality of the environment $\mathrm{s}$ does not provide a reliable and detailed portrait of the quality in the groups. For this reason, it is essential to consider the details and descriptions of each indicator evaluated and how the instrument is applied to plan and improve the quality.

This study revealed that higher levels of Affordances indicate better motor development, whereas lower levels of Affordances suggest delayed motor development, indicating that the daycare environment influences the child's motor development, especially with daily activities and toys. Good physical conditions and stimulating environments available for children in the age range were essential to promote motor development, and the quality of the environment in the schools is a predictive factor.

The children attending the CMEIs presented excellent motor development, the teachers and staff presented adequate training, the infrastructure of the schools was appropriate, and good interaction took place between the teachers and children. However, some environments were more likely to present suspected delayed motor development.

Thus, it is vital to promote integrated motor development with socioemotional and cognitive skills, qualifying preschool environments, and training professionals who work in preschools.

\section{Authors' contribution}

Lovison K, Moreira HSB, Silva J planned and performed the data collection. Scorzafave LGDS performed the statistical analysis. Mello DF worked on the manuscript. All the authors approved the manuscript 's final version.

developing brain. Neuropsychopharmacol. 2016; 41: 17796.

6. Brito PR, Lye S, Yousafzai A, Matthews SG, Vaivada T. Nurturing care: promoting early childhood development. Lancet. 2017; 389: 91-102.

7. Morais RLS, Carvalho AM, Magalhães LV. The environmental contexto and the child development: Brazilian Studies. J Phys Educ. 2016; 27: 15-9.

8. Ghassabian A, Sundaram R, Bell E, Bello SC, Kus C, Yeung E. Gross motor milestones and subsequent development. Pediatrics. 2016; 1: 20154372.

9. Serdarevic F, Ghassabian A, Van Batenburg-Eddes T, 
Tahirovic E, White T, Jaddoe VWV, Verhulst FC, Tiemeier $\mathrm{H}$. Infant neuromotor development and childhood problem behavior. Pediatrics. 2017; 6: 20170884

10. Pluciennik GA, Lazzari MC, Chicaro MF. Fundamentos da família como promotora do desenvolvimento infantil: parentalidade em foco. São Paulo: Fundação Maria Cecília Souto Vidigal, 2015.

11. Black MM, Walker SP, Fernald LCH, Andersen CT, Digirolamo AM, Chunling, Dana CM, Gunter F, Yursa RS, Shiffman J, Devercelli A, Wodon QT, Várgas-Baron E, Grantham-McGregor S. Early childhood development coming of age: science through the life course. Lancet. 2017; 389 (10064): 77-90.

12. Campos MM, Esposito YL, Bhering E, Gimenez N, Abuchaim B. A qualidade da educação infantil: um estudo em seis capitais brasileiras. Cad Pesq. 2011; 41: 20-54.

13. Barros RP, Carvalho M, Franco S, Mendoça R, Rosalem A Uma avaliação do impacto da qualidade da creche no desenvolvimento infantil. PPE. 2011; 41: 213-32.

14. Müller AB, Valentini NC and Bandeira PFR. Affordances in the home environment for motor development: validity and reliability for the use in daycare setting. Infant Beh Develop. 2017; 20: 138-45

15. Caçola P, Gabbard C, Monteiro MI, Santos DC. Further development and validation of the affordances in the Home Environment for Motor Development-Infant Scale (AHEMD-IS). Phys Ther. 2015; 95: 901-23.

16. Saccani R, Valentini NC. Reference curves for the Brazilian Alberta Infant Motor Scale: percentiles for clinical description and follow-up over time. J Pediatr. 2012; 88: 40-7.

17. Piper MC, Darrah J. Motor assessment of the developing infant. Philadelphia: WB Saunders Company, 1994.
18. Felfe C, Lalive R. Early child care and child development: for whom it works and why. Centre for Economic Policy Research. 2013; 1: 47.

19. True L, Pfeiffer KA, Dowda M, Williams HG, Brown WH, O'Neil JR. Motor competence and characteristics within the preschool enviroment. J Sci Med Sport. 2017; 8: 751-5.

20. Campos MM, Rosemberg F. Critérios para um atendimento em creches que respeite os direitos fundamentais das crianças. 6 ed. Brasília, DF: MEC, SEB, 2009.

21. Yoshikawa H, Leyva D, Snow CE, Trebiño E, Barata MC, Weiland C. Experimental impacts of a teacher professional development program in Chile on preschool classroom quality and child outcomes. Develop Psyc. 2015 3: 309-22.

22. Bernal R, Ramírez M. Improving the quality of early childhood care at scale: the effects of "From Zero to Forever". World Dev. 2019; (118): 91-105.

23. Pedrosa C, Caçola P, Carvalhal MIM. Factors predicting sensory profile of 4 to 18 month old infants. Rev Paul Pediatr. 2019; (33):160-166

24. Almeida CS, Valentini NC. Nursery's environment and the intervention in babies' development. Motr. 2013; 9: 22-32.

25. Vitta FCF, Sgaviolli AJR, Scarlassara BS, Novaes CFM, Cruz GA, Moura MM. National scientific production in the special education area and daycare. Rev Bras Educ Espec. 2018; 24 4: 619-36.

26. Felfe C, Zierrow L. From dawn till dusk: Implications of full-say care for children's development. Lab Econo. 2018; 55: $259-81$.

27. Beijers R, Jansen J, Riksen-Walraven M, Weerth C. Nonparental care and infant health: do number of hours and number of concurrent arrangements matter? Early Hum Dev. 2011; 87: 9-15.

Received on August 31, 2020

Final version presented on May 10, 2021

Approved on June 18, 2021 